\title{
The Impact of Government Policy on Higher Education International Student Recruiters
}

\section{Melissa James}

University of Prince Edward Island, Canada.

\begin{abstract}
This paper explores higher education actors involved in the recruitment of internationalstudents and their perceptions of their home country's government policy on their practice. It examines case study institutions from three countries Canada, Hong Kong, and the United Kingdom. This study shows higher education institutions do not exist in a vacuum and regardless of their location, government policy shapes perceptions for international student recruiters who believe that government policies contribute or hinder their practice. All of the participants, regardless of location, show a high level of awareness of government policy that greatly shapes their strategies. More specifically, recruiters find tensions arising from these policies with government shaping recruitment priorities and restricting or instigating competitive responses, while their institutions do not challenge government policy (enough). The findings suggest that government policies establish the "playing field" for recruiters as they attempt to navigate an increasingly competitive environment but at the same time, these perceptions are highly localized and need to be understood in their individual settings.
\end{abstract}

Keywords: internationalization; government policies; recruiters; students. 


\section{Introduction}

This study compares higher education institutions (HEI) from different parts of the world to understand how their government policy frameworks shape practice for international student recruiters. It argues that international student recruitment for HEIs is complex due to government policies and these policies may have direct or in-direct impacts on the practice. There is much unknown about how actors involved in international student recruitment activities conceptualize and respond to government forces. Other studies argue for greater understanding of international student recruitment activities in HEIs from the supply-side and the challenges faced by those involved in the practice as institutions aim to manage government policy changes and other forces on their practice (Asaad et al., 2015; Findlay et al., 2017; Mosneaga \& Agergaard, 2011; O’Connor, 2017; Zinn \& Johansson, 2015). There is a need for more critical perspectives on international student recruitment practice to offer accounts and descriptions from those involved and how they interpret government policies in their day-to-day practice. This study will provide these perspectives and will further our understanding of how government policy shapes international student recruitment from the supply-side (Findlay et al., 2017).

\section{Literature Review}

The link between government policy and international student recruitment is currently not well understood (O’Connor, 2017; Sá \& Sabzalieva, 2017). O'Connor (2017) studied international strategy from the student and institutional perspective at an Irish university and found there are conflicts in the practice of recruiting international students that are highly local. Their national and local institutional policies are designed to attract international students for economic recovery and diversity, but the institution had a passive acceptance of these students, impacting the international student experience on campus. This study examines one institution in Ireland and sheds light on practice problems associated with government policies that affect the recruitment of international students and suggests further studies of institutions in other jurisdictions will hold value (O'Connor, 2017). This study supports this argument that further research is necessary to understand government policies in the context of local, institutional dynamics and that institutional actors shape practice based on their interpretations of these policies.

These practices suggest a competitive and marketized landscape at a national level that contributes to local, institutional approaches to international student recruitment. Previous studies show marketization and government policy shaping higher education and argue it is important to examine institutional level impacts in the context of their government policy frameworks (Cudmore, 2005; Marginson, 2017; Mosneaga \& Agergaard, 2011, O’Connor, 2017, Sá \& Sabzalieva, 2018). Beech (2018) explored international student recruitment staff 
from ten UK institutions. This study examined changes to the UK visa system and the impacts on recruitment methods through the relationships staff had with educational agents. It found that student mobility is an industry driven by market forces and institutional responses are important in facilitating student mobility. Geddie (2015) furthers this argument in a study of twenty-nine higher education policymakers in the UK and Canada and found that national policies change and evolve at local levels and that there are "perceived competitive relations between places and actors" (p. 245). This suggests that actors' perceptions at local, institutional levels are important in conceptualizing government policy. Similarly, Findlay et al. (2017) study of stakeholders in the UK higher education sector show that institutions and inter-university organizations have different motivations to attract international students to the UK and suggest that financial motives and the drive to be "globally excellent" serves to position institutions globally to attract international students. At the same time, respondents in the study perceived government policy to restrict these objectives. Findlay et al. (2017) is a comprehensive study of international students who chose to study in the UK and a small set of actors involved in attracting students to the UK. Findlay et al. (2017) argue more studies need to examine the institutional or supply-side perspectives of international student recruitment as there is limited literature on internal operations of HEIs and how they perceive government policies on their practice. This study extends studies such as Findlay et al. (2017) and O'Connor (2017) by taking the supply-side view (or institutional view) of international student recruitment practice by exploring practitioners, in three different countries, as a basis to compare their perceptions. It does this by examining complexities such as government policy contexts and how practitioners view these policies impacting their practice. These studies show that system actors may have different perspectives on government policies, but little is understood about how these policies are perceived. Furthermore, there are limited comparisons of international student recruitment practitioners from different countries. This study explores the local, institutional response government policies facing practitioners of international student recruitment in Canada, Hong Kong, and the UK.

\section{Methods}

The study examines three institutions from three separate countries in an international comparison. The main research question guiding this study is how do practitioners' view of government policies as influencing their international student recruitment practice? As such, the primary data for this study considers the views and perspectives of the participants nvolved in international student recruitment in each case in the context of their national policy frameworks that existed in 2017. Therefore, semi-structured interviews with international student recruitment practitioners were the primary data collection method in this study while document analysis of government policies was used to inform the interview guide and 
contributed to understanding the context and settings. This paper uses case study method to explore the practice of international student recruitment at three HEIs and examines the perspectives of participations thereby creating a cross-case study analysis (Stake, 2013). Case study research is useful for institutional management as it allows for several data sources in real-world contexts, where there was no previous research before (Jensen \& Rodgers, 2002). There are few empirical studies on HEIs, and the case study approach provides the flexibility to examine multiple sources and to gather appropriate qualitative data for the study.

The case study sites are the University of Prince Edward Island, Canada (UPEI); the University of Hong Kong, Hong Kong (HKU) and Lancaster University, United Kingdom. Each of these institutions actively recruits international students (both graduate and undergraduate). An important factor in choosing the case studies was the different national settings that shape international student recruitment presenting opportunities to compare institutions. While each institution showed that $20-26 \%$ of their student population is international, recruiters may view their practices differently and face similar or different challenges in their practice as a result of these policies. These unique circumstances contribute to understanding government policy influence in each case by recognizing these macro-level policies may have different impacts than anticipated and these impacts on international student recruitment have not been previously explored in an international comparison of three separate countries.

The sample consisted of participants within each institution who are directly involved in attracting prospective international students. These are typically individuals with titles such as recruiter, international manager, or overseas manager. Within each institution, the sample was purposive in that only those individuals who had direct involvement with students were invited to participate. The size of the sample varied according to the number of individuals involved in the practice until a saturation point was reached, meaning a sufficient number participants representing the functional areas of the collective activity were interviewed (Guba \& Lincoln, 1994). This point was measured in all institutions, as there were a finite number of potential participants. As such, the study involved three interviews at the University of Hong Kong case study (population three); four interviews at the UPEI case study (population six); and seven interviews at Lancaster University (population eleven). This variation in size was reflective, not only of the level of effort and resources dedicated to international student recruitment but also how the institutions assigned responsibilities. In total, the study involved fourteen interviews across the three case study locations. The interviews were conducted in-person and each one recorded. 


\section{Findings}

The findings show the three case study HEIs share similar perceptions of government policy on their practice namely that these policies acti as a"playing field" and restrict their ability to compete and respond to competitive markets. However, the participants' views of national policies suggest local context is needed. For example, UPEI understood that government played a central role in funding the jurisdiction's only university and the participants viewed the government as an enabler of international student recruitment. Meanwhile, the other two institutions viewed government and their policies as a constraint and participants viewed government as negatively impacting their practice through policies. The subjects at HKU and Lancaster believed the policies inhibited international student recruitment efforts through the quota for HKU and immigration policy for Lancaster University. These views of government were unique to each case study as the policies and relationships with government varied in each setting (Beech, 2018, Findlay et al., 2017, O’Connor, 2017).

The Hong Kong government through the UGC established the quota for international students to HKU and this quota system monitored compliance. The quota served to mediate international student recruitment by limiting the number of students who can attend the institution. As such, government controlled the nature and extent of international student recruitment at HKU. The institution recruited students by adopting strategies that focused on the institutional brand and by attracting "top students". At the same time, the quota limited the scope of international student recruitment for the institution, both in financial and human terms. There was less incentive to dedicate resources to actual recruitment practice when the quota limited capacity and financial gains (Asaad et al., 2015). The quota also constrained the choice of markets that the recruiters visited and forced the recruiters to direct resources to China, limiting diversity and choice of top students. "Mainland China is not international, but it's not local" (interviewee 3, HKU). This government view of international students directed China to be the main market for $\mathrm{HKU}$, but it also created divergent priorities for the institution. "You have to prioritize and you're obviously trying to get as many representation as you can within the 600 number, this magic number that's been hanging over our head" (interviewee 3, HKU). Six hundred were the maximum number of students that HKU could enroll based on the quota system. As such, international student recruitment strategies were adopted based on the parameters established within the quota system and necessitated the recruiters to make decisions that adhered to the six hundred limit while ensuring Mainland Chinese students were a main contributor to their target.

In the UK, Lancaster also experienced government policy constraints in the form of the removal of the post-study work visa and the on-going Brexit discourse. Participants discussed government policy and media communication as shaping perceptions amongst prospective students and this created challenges for recruiters as they attempted to overcome these negative messages. 
"It is just negative media that gets out. A few years ago, was the close of the post study work visa. Messaging went out to say that UK is closed (closed borders for students), you can't work you got to go home. So I think there are certain markets where India being one, the students are expected to stay in country, get some work experience, get a job, earn some money, pay off some of their debts before returning home. So, Government policy now is restricting that" (interviewee 8 , Lancaster).

The participants discussed the challenges of negative government policies as the realities they faced as they entered markets or established recruitment priorities. Recruiters believed the policies and discourse is well known amongst prospective students and that recruiters had to overcome negative perceptions of the UK in their approach to students.

Meanwhile, in Canada, the national and provincial government had placed considerable importance on recruiting international students for economic benefits. "We need to import talent, train them, and encourage them to stay, develop businesses and contribute to the economy. (interviewee 1, UPEI) This neo-liberal approach to attracting international students created a national policy environment that encouraged the international student recruitment game for HEIs in Canada. This raised expectations for institutions to attract students for national economic interests but also for institutional sustainability. At UPEI, 50\% of their operating budget came from self-sourced revenues such as students ("Short-term Enrolment Plan", 2016). Even though government funding may be challenging for HEIs, the recruiters at this institution viewed immigration and marketing policies from all levels of government as highly positive.

\section{Discussion and Conclusion}

The case studies exist in different government policy contexts that influence their practices of attracting international students. In Hong Kong, international student recruitment was highly controlled with a quota system while in Canada it has become progressively more flexible to attract international students to study and work post-graduation. At the same time, the UK is experiencing a shifting policy environment in immigration that respondents describe as impacting the recruitment of international students. The findings show that the institutions do not exist in a vacuum and regardless of their location, government policy shapes perceptions for recruiters who believe that government policies contribute or hinder their practice. All of the participants, regardless of location, show a high level of awareness of government policy that greatly shapes their strategies. "Key export trends (e.g. competition, regulation) should be constantly monitored...to formulate marketing strategies that are aligned to changes in export market conditions" (Asaad et al., 2014, p. 156). This study provides insight into how recruiters perceive government policy impacting their international student recruitment practice. These findings confirm the importance of close 
monitoring of government policy for international student recruitment (Asaad et al., 2013, 2014, 2015; Hemsley-Brown \& Oplatka, 2010; Marginson, 2017, Sá \& Sabzalieva, 2018) and further suggest that the impact of policy be discussed and understood amongst all actors involved in the practice (Ross et al., 2013). As HEIs expand their recruitment efforts, greater attention needs to be paid to these investments. Fundamentally, all colleges and universities do the same things and deliver the same things. This sets up a race to build more and grow larger" (Sickler, 2017, p. 4). This should assist institutions to contextualize to national policy changes on their practices thereby enhancing their understanding of the impacts of these investments.

These findings are of value to policy-makers, administrators, and researchers, regardless of country or HEI. These insights may be used to understand national policy changes on institutional strategy and enable institutions and governments to collaborate in positive manner. This study showed that there is value in examining actors' perceptions of government policy on their international student recruitment efforts. Additional case study locations in other parts of the world may further these findings. Future studies should consider how national policy shapes different types of practices also may help institutions improve performance. Previous literature shows there is little research examining the internal operations of HEIs from different jurisdictions and the lack of different actors' perspectives on international student recruitment practice (Findlay et al., 2017; Ross et al., 2007, 2013). Expanding the research to different jurisdictions and including different institutional practices such as research and teaching may add insights into the complexity facing higher education and its practitioners as they operate in global environments.

\section{References}

Asaad, Y., Melewar, T. C., \& Cohen, G. (2015). Export market orientation behavior of universities: The British scenario. Journal Of Marketing For Higher Education, 25(1), 127- 154. doi: 10.1080/08841241.2015.1031315

Beech, S. E. (2018). Adapting to change in the higher education system: international student mobility as a migration industry. Journal of Ethnic and Migration Studies, 44(4), 610625.

Cudmore, G. (2005). Globalization, internationalization, and the recruitment of international students in higher education, and in the Ontario Colleges of Applied Arts and Technology. Canadian Journal of Higher Education, 35(1), 37-60.

Findlay, A. M., McCollum, D., \& Packwood, H. (2017). Marketization, marketing and the production of international student migration. International Migration, 55(3), 139-155.

Geddie, K. (2015). Policy mobilities in the race for talent: Competitive state strategies in international student mobility. Transactions of the Institute of British Geographers, 40(2), 235-248. 
Guba, E. G., \& Lincoln, Y. S. (1994). Competing paradigms in qualitative research. Handbook of qualitative research, 2(163-194), 105.

Hemsley-Brown, J., \& Oplatka, I. (2010). Market orientation in universities: A comparative study of two national higher education systems. International Journal of Educational Management, 24(3), 204-220.

Jensen, J. L., \& Rodgers, R. (2001). Cumulating the intellectual gold of case study research. Public Administration Review, 61(2), 235-246. doi: 10.1111/0033-3352.00025

Marginson, S. (2017). Global trends in higher education financing: The United Kingdom. International Journal of Educational Development. (in-press). Recruitment and marketing. International Journal of Educational Management, 20(6), 466-479. doi: $10.1108 / 09513540610683711$

Mosneaga, A., \& Agergaard, J. (2012). Agents of internationalisation? Danish universities' practices for attracting international students. Globalisation,

O’Connor, S. (2017). Problematising strategic internationalisation: tensions and conflicts between international student recruitment and integration policy in Ireland. Globalisation, Societies and Education, 1-14.

Ross, M., Heaney, J. G., \& Cooper, M. (2007). Institutional and managerial factors affecting international student recruitment management. International Journal of Educational Management, 21(7), 593-605.

Ross, M., Grace, D. and Shao, W. (2013). Come on higher ed... get with the program! A study of market orientation in international student recruitment. Educational Review, 65(2), 219-240. doi: 10.1080/00131911.2012

Sá, C. M., \& Sabzalieva, E. (2018). The politics of the great brain race: public policy and international student recruitment in Australia, Canada, England and the USA. Higher Education, 75(2), 231-253.

Sickler, J. (2017). People don't buy different. Stamats. Retrieved from http://www.stamats.com/stamats-insights/2017/people-dont-buy-different

Stake, R. E. (2013). Multiple case study analysis. New York, NY: Guilford Press.

Zinn, M., \& Johansson, H. (2015). Student recruitment for the mobile generation: An exploratory study of mobile marketing practices in the international higher education industry (Master's thesis). Jönköping International Business School, Jönköping, Sweden. 